\title{
Kinetics of biomass low-temperature pyrolysis by coats-redfern method
}

\author{
Dariga Altynbaeva ${ }^{1, *}$, Alexander Astafev ${ }^{1}$, and Roman Tabakaev ${ }^{1}$ \\ ${ }^{1}$ National Research Tomsk Polytechnic University, 634050 Tomsk, Russia
}

\begin{abstract}
Energy is one of the main sources of environmental pollution. In this regard, the world scientific community seeks to reduce its negative impact on human health and nature. To do this, some of the organic raw materials, which are fuel for power plants, are gradually replaced by renewable resources, in particular - biomass. The combustion of biomass by traditional methods is accompanied by high operating costs, which leads to the conclusion that it is necessary to process it into energyvaluable products. The development of one of the most promising such directions - thermal processing - requires studying the thermophysical properties of biomass and studying its kinetics of decomposition. The aim of this work is to estimate the activation energy of thermal decomposition of biomass by the method of Coats-Redfern.
\end{abstract}

\section{Introduction}

As is known [1], the power engineering is one of the main sources of environmental pollution. In which connection, the power stations, used coal and brown coals, anthracites as fuel, are cause damage to the environment. According to the World Health Organization $[1,2]$, air pollution leads to premature deaths of several million people per year, what is comparable to the size of a large metropolis.

In this regard, developed and developing countries (for example, the USA, Finland, France, Canada, etc. [3]) announced a policy by gradually fossil organic fuels use reducing for energy production. Replacement of organic fuel should be carried out by increasing the share of renewable energy sources (RES), such as sun, wind, biomass, etc. The use of RES will increase the ecological purity of energy production; will reduce the external energy dependence of countries, which not have own fuel resources; will stimulates the development of local and regional production; will contribute to the development of the agro-industrial complex and creation of new jobs [4]. In 2015, 7.1\% of electricity was generated on the basis of renewable energy (excluding hydropower) [5]. At the same time, the share of such output will increase to $20 \%$ by 2020 at the plan of the European Union [6].

Biomass is considered as one of the most important and promising RES, what is due to its ubiquity and large volumes of formation. It is recognized that biomass is neutral in the carbon dioxide circulation: when burning biomass, the same amount of carbon dioxide is

\footnotetext{
* Corresponding author: dba10@tpu.ru
} 
formed, which was absorbed during her life as a result of photosynthesis. The sulfur is practically absent in biomass content, what ensures the low $\mathrm{SO}_{\mathrm{x}}$ emissions at the time of its burning [7]. At present time, the share of biomass in the world fuel and energy balance is about $9.7 \%[5]$.

However, the burning of biomass by traditional methods is accompanied by a number of problems, which prevent its wide using in the energy sector. For example, the biomass in a natural state has a high humidity, which reaches to $30.4-79.7 \%$ [8], what leads to a low calorific value in terms of the operating state. In addition, such a high humidity of biomass leads to its caking, sticking during a transportation, and in winter - to freezing, what additionally complicates the process of transportation and unloading of raw materials [9]. Some types of biomass (for example, bran) are prone to slagging of heating surfaces during combustion [10], as a result of which the service life of the fuel-burning equipment is reduced and the cost of repair works is increased. The heterogeneous fractional composition of the biomass leads to a high value of the failure through the grate at layer combustion, increasing the losses with mechanical underburning $\left(\mathrm{q}_{4}\right)$ and thereby reducing the overall boiler efficiency. Thus, the energy use of biomass by traditional methods of combustion is accompanied by high operating costs, which prevents its widespread use as fuel.

The previous studies [11] are shown the prospects for thermal processing of biomass into energy-valuable products, such as high-calorific solid fuel, liquid biofuels or flammable gas. The combustion of these products, even by traditional methods, is highly efficient and requires significantly less cost than using of raw materials in their natural state.

The various studies of biomass thermal processing by physical experiment is a labourintensive process required a large time and material resources. The construction of a mathematical model and the conduction on its basis of numerical studies is contributed to increasing of productivity and study economy. The development of model for thermal processing is required of study a large number of physical and chemical quantities, which necessary to obtain of reliable and adequate results, in particular the activation energy.

In this regard, the purpose of this paper is evaluation of biomass thermal decomposition activation energy by Coats-Redfern method.

\section{Material and methods}

Several samples of biomass were considered in this work: straw, chips from various types of wood and low-lying peat (Sukhovskoe deposit, Tomsk region). The samples were previously dried to air-dry state (Table 1).

Table 1. The humidity of researched biomass samples

\begin{tabular}{|c|c|c|c|}
\hline Biomass & Straw & Chips & Peat \\
\hline Humidity W $\mathrm{W}^{\mathrm{a}}, \%$ & 8.5 & 8.5 & 11.5 \\
\hline
\end{tabular}

The differential thermal (DTA) and thermogravimetric (TGA) analyzes with thermal analyzer STA 449C Jupiter (Netzsch, Germany) were performed to evaluation of the activation energy. The samples were heated at a rate of $10^{\circ} \mathrm{C}$ per minute (averaged heating rate according to the generally accepted standard of fuels semi-coking of ISO 647-74), the temperature range of the experiment was from $20^{\circ} \mathrm{C}$ to $600^{\circ} \mathrm{C}$. The weight of samples was $50 \mathrm{mg}$. Analyzes were performed in an inert medium (helium) in order to exclude the influence of oxidative reactions on the results of the study.

The activation energy was calculated by the method of A. Coats and J. Redfern [12]. The method is based on the hypothesis about that the single-stage first-order reactions, submitted to the Arrhenius laws occur, are procced at the time of solid fuels thermal 
decomposition. The activation energy equation according to Coats-Redfern has the following form:

$$
\ln \left[\frac{-\ln (1-\alpha)}{T^{2}}\right]=\ln \left[\frac{A R}{\beta E_{a}}\left(1-\frac{2 R T}{E_{a}}\right)\right]-\frac{E_{a}}{R T}
$$

where $\alpha=\frac{m_{0}-m_{i}}{m_{0}-m_{\mathrm{K}}}$

$m_{0}-$ mass of reaction start, $\mathrm{kg}$;

$m_{\kappa}-$ mass of reaction finish, $\mathrm{kg}$;

$m_{i}-$ mass in the period of $i, \mathrm{~kg}$;

$\alpha$ - conversion level;

$T$ - temperature of heating, $\mathrm{K}$;

$A$ - pre-exponential coefficient;

$R$ - gas constant, $\mathrm{J} /(\mathrm{mole} \cdot \mathrm{K})$;

$E_{a}$ - activation energy, $\mathrm{kJ} / \mathrm{mole}$;

$\beta$ - reaction rate, $\mathrm{K} / \mathrm{min}$.

Further, the dependency diagram $\ln \left(-\ln (1-\alpha) / T^{2}\right)$ from $1 / T$ is constructed in accordance with the formula for the first-order reaction, its result is a straight line, the slope of this line is $E_{a} / R$, and the intersection point of this line with the axis $\ln \left(-\ln (1-\alpha) / T^{2}\right)$ is equal to $\ln \left(A R / \beta E_{a}\right)$.

\section{Results and discussion}

The results of DTA and TGA for researched samples are shown in Fig. 1. It can be seen that during heating from 20 to $140-150^{\circ} \mathrm{C}$ there occurs moisture evaporation from the samples, which was accompanied by an endothermic peak. The thermal decomposition of biomass starts at a temperature of $160-180^{\circ} \mathrm{C}$ and accompanied by its mass decrease (Fig. 1, TG curve). The temperature $240^{\circ} \mathrm{C}$ was the beginning for main exothermic reactions, terminating at $580^{\circ} \mathrm{C}$, for straw and chips. With the thermal decomposition of peat samples, two exothermic peaks were observed: first $-200-330^{\circ} \mathrm{C}$, second $-380-560^{\circ} \mathrm{C}$.

The graphical construction of the Coats-Redfern equation is shown in Fig. 2. It can be seen that the biomass samples decomposition proceeds in two stages. The calculation of the activation energy for each stage on dependence of biomass type is given in Table 2.

Table 2. Activation energy of thermal decomposition

\begin{tabular}{|c|c|c|c|c|c|c|c|}
\hline \multirow[t]{2}{*}{ Biomass } & \multicolumn{2}{|c|}{$\begin{array}{l}\text { Activation } \\
\text { energy } E_{a} \text {, } \\
\mathrm{kJ} / \mathrm{mole}\end{array}$} & \multirow{2}{*}{$\begin{array}{c}\text { Start of } \\
\text { decomposition } \\
t_{0},{ }^{\circ} \mathrm{C}\end{array}$} & \multirow{2}{*}{$\begin{array}{c}\text { Transition } \\
\text { temperature } \\
\mathrm{t}_{\mathrm{i},},{ }^{\circ} \mathrm{C}\end{array}$} & \multirow{2}{*}{$\begin{array}{c}\text { Finish of } \\
\text { decomposition } \\
t_{\mathrm{K}},{ }^{\circ} \mathrm{C}\end{array}$} & \multicolumn{2}{|c|}{$\begin{array}{l}\text { Pre-exponential } \\
\text { coefficient, } \mathrm{c}^{-1}\end{array}$} \\
\hline & $\mathrm{I}$ & II & & & & $\mathrm{I}$ & II \\
\hline straw & 74.2 & 29.1 & 162 & 350 & 595 & 5919 & 8213333 \\
\hline chips & 85.0 & 11.7 & 180 & 366 & 575 & 61773 & 5480814 \\
\hline peat & 68.9 & 18.9 & 180 & 340 & 565 & 2537 & 3629208 \\
\hline
\end{tabular}

The analysis of obtained data (Table 2) is shown that the activation energy for the first stage have a greatest value for the sample of chips, a smallest - for sample of peat. At the second stage, the straw has a greatest value of the activation energy, and the chips - a smallest. Considering that the activation energy is the energy, which necessary for breaking bonds between molecules, the most energy-consuming raw material for processing (including both stages) is straw, and less energy-consuming - peat.

The obtained data are accorded with the results of previous studies by other authors [13]. 


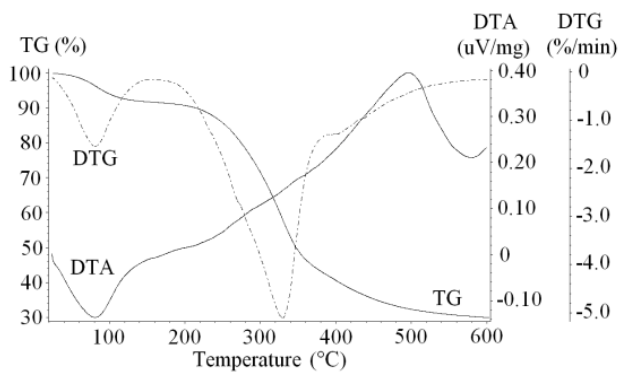

(a)

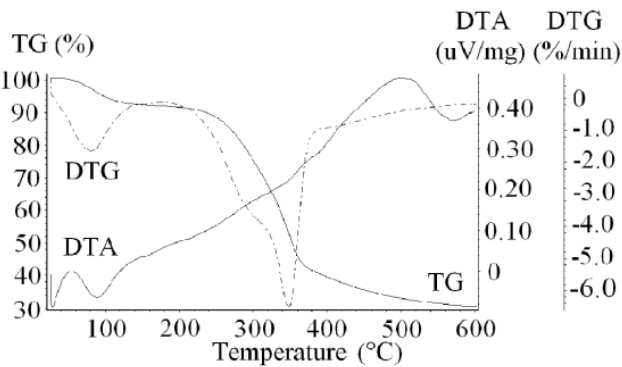

(b)

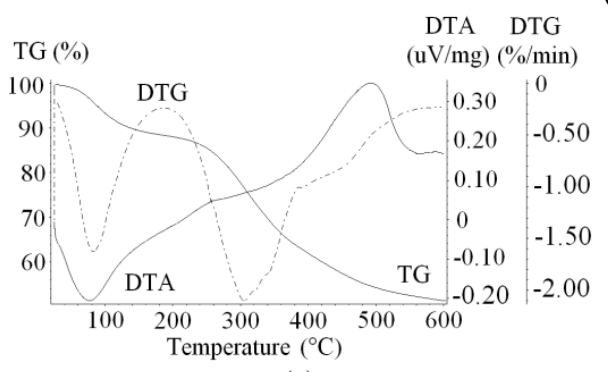

(c)

Fig. 1. Curves of DTA analysis: $a-$ straw, $b-$ chips, $c-$ peat.

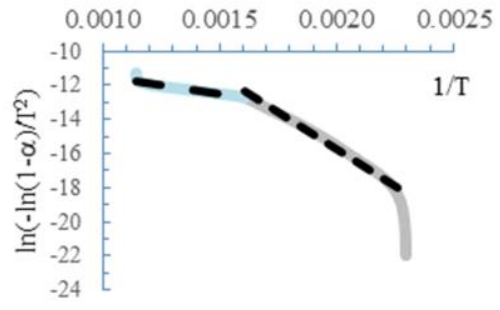

(a)

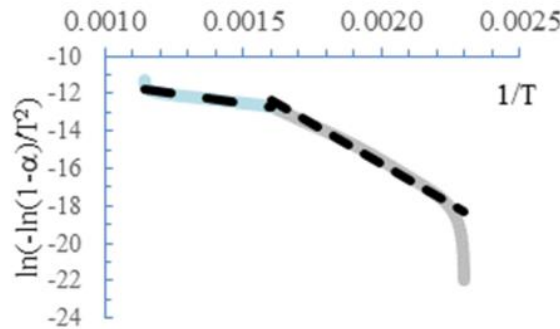

(b)

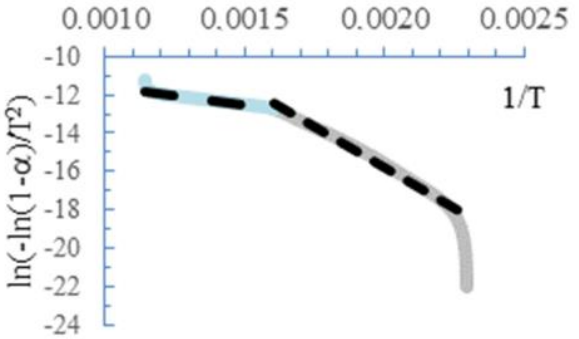

(c)

Fig. 2. The dependency $\ln \left(-\ln (1-\alpha) / T^{2}\right)$ from $1 / T: a-$ straw, $b-$ chips, $c-$ peat.

\section{Conclusions}

The results of DTA and TGA for biomass samples of several types (straw, chips and peat) are given in this paper. The activation energy of the biomass thermal decomposition is calculated with using of the Coats-Redfern method, developed for evaluation of the thermal analysis results. It has been established that the thermal decomposition of biomass proceeds in two stages: the first stage start at temperature $162-180^{\circ} \mathrm{C}$ and finish at temperature 340 - 
$366^{\circ} \mathrm{C}$; the second stage - from $340-366^{\circ} \mathrm{C}$ to $565-595^{\circ} \mathrm{C}$. Wherein, the most energyconsuming raw material for thermal processing is straw and less energy-consuming is peat.

The reported study was funded by RFBR according to the research project No. 18-38-00648.

\section{References}

1. World Energy Outlook Special Report. Energy and Air Pollution (International Energy Agency, Paris, 2016)

2. J. Lelieveld, J.S. Evans, M. Fnais, D. Giannadaki, A. Pozzer, Nature 525, 367 (2015)

3. O.S. Popel, B.F. Reutov, A.P. Antropov, Therm. Eng. 57, 909 (2010)

4. J.L. Miguez, L.M. Lopez-Gonzalez, J.M. Sala, J. Porteiro, E. Granada, J. C. Moran, M.C. Juarez, Renew. Sust. Energ. Rev. 10, 225 (2006)

5. International Energy Agency (IEA): Key world energy statistics (Chirat, France, 2017)

6. EU Road Map: http://europa.eu/legislation_summaries/energy/renewable_energy/ 127065_en.htm 2007 (Accessed 01.03.2018)

7. S. Sofer, O. Zaborski, Biomass conversion processes for energy and fuels (Plenum Press, New York, 1981)

8. S. V. Vassilev, C. G. Vassileva, V. S. Vassilev, Fuel 158, 330 (2015)

9. A. D. Uchitel, M. V. Kormer, V. P. Lyalyuk, I. A. Lyakhova, E. O. Shmel'tser, Y.I. Vititnev, Coke Chem. 56, 167 (2013)

10. M. Yu. Chernetskiy, A. A. Dekterev, A. Burdukov, Journal of Siberian Federal University. Engineering \& Technologies 6, 625 (2013)

11. R. Tabakaev, I. Shanenkov, A. Kazakov, A. Zavorin, J. Anal. Appl. Pyrolys. 124, 94 (2017)

12. A. W. Coats, J. P. Redfern, Nature 201, 68 (1964)

13. C. Lu, W. Song, W. Lin, Biotechnol Adv. 27, 583 (2009) 